\title{
Analyzing microporosity with vapor thermogravimetry and gas pycnometry
}

\author{
A. Petra Dral, Johan E. ten Elshof \\ MESA+ Institute for Nanotechnology, University of Twente, P.O. Box 217, 7500 AE Enschede, The Netherlands
}

\section{A R T I C L E I N F O}

\section{Article history:}

Received 19 May 2017

Received in revised form

4 August 2017

Accepted 14 September 2017

Available online 15 September 2017

\section{Keywords:}

Microporosity

Analysis

Adsorption

Thermogravimetry

Pycnometry

Zeolite

\begin{abstract}
A B S T R A C T
The complementary use of thermogravimetry and pycnometry is demonstrated to expand the toolbox for experimental micropore analysis $<1 \mathrm{~nm}$. Thermogravimetry is employed to assess the uptake of water, methanol, ethanol, 1-propanol and cyclohexane vapors in microporous structures at room temperature and derive quantitative micropore volumes and minimum pore entrance sizes together with qualitative information on surface chemistries. Pycnometry is employed to measure the uptake and adsorption of helium, argon and nitrogen gas in microporous structures at room temperature and derive semiquantitative surface-to-volume ratios, surface areas and micropore cavity sizes and qualitative information on the surface chemistries. The method is validated and calibrated by applying it to a series of zeolites with known micropore structures. The results are compared with data from conventional $\mathrm{N}_{2}$ adsorption at $-196{ }^{\circ} \mathrm{C}$ and $\mathrm{CO}_{2}$ adsorption at $0{ }^{\circ} \mathrm{C}$. Main advantages of the demonstrated method are that diffusion limitations due to cryogenic temperatures are eliminated, adsorption is studied with non-polar gases, micropore cavity sizes are probed separate from micropore entrances and data can be interpreted in a straightforward fashion without requiring theoretical models on molecular behavior. Micropores $<1 \mathrm{~nm}$ can thus be analyzed with increased accuracy as compared to conventional adsorption isotherm analysis.
\end{abstract}

(c) 2017 Elsevier Inc. All rights reserved.

\section{Introduction}

Analyzing microporosity is important for the design and implementation of materials, e.g. for molecular sieving membranes, catalysts, adsorbents and pharmaceutics [1-4]. Microporosity originates from intrinsic material properties as well as material synthesis and processing, which yields extensive tunability but also requires a high level of control during preparation. In addition to the field of material engineering micropore analysis is also relevant in other areas, e.g. natural resources and food, to evaluate material characteristics [5-8]. A wide range of experimental analysis techniques is employed to obtain information on micropore size, volume, surface chemistry and surface area that can roughly be divided into three classes: radiation porosimetry, permeation porosimetry and adsorption porosimetry. Though not exhaustive, various experimental techniques are shortly

\footnotetext{
* Corresponding author.

E-mail addresses: a.p.dral@utwente.nl (A.P. Dral), j.e.tenelshof@utwente.nl (J.E. ten Elshof).
}

discussed below to sketch the possibilities of commonly used methods and the added value of the approach presented in this study.

Radiation porosimetry analyzes micropore characteristics via radiation events inside micropores or at the interface between micropore and wall. Small-angle and wide-angle X-ray scattering employs scattering of X-rays at the interface between micropore and wall and provides information on micropore surface areas and micropore sizes down to $0.3 \mathrm{~nm}$ [9-12]. Small-angle neutron scattering provides similar information and is also sensitive to light elements [13]. Interpretation of scattering data usually requires sample details such as the particle shape and structure factor of the system to be known. Positron annihilation spectroscopy monitors the lifetime and decay of positronium inside micropores. This yields depth-resolved information on micropore size and volume and the electronic structure of the pore walls, being able to probe pores as small as positronium (Bohr radius $=0.053 \mathrm{~nm}$ ) [14-18]. A drawback is that it requires a radioactive positron source. Radiation porosimetry targets all micropores regardless of them being interconnected or isolated. 
Permeation porosimetry evaluates micropore characteristics more tangibly via gaseous or liquid probe molecules that permeate through the micropore structure and probes the bottlenecks along continuous permeation paths from one side to the other. Dead-end and isolated porosity is neglected. Molecular sieving membrane permeation gives information on pore entrance sizes in the range of the probe molecules, which is $0.3-0.4 \mathrm{~nm}$ for commonly used gases such as $\mathrm{He}, \mathrm{H}_{2}, \mathrm{~N}_{2}$ and $\mathrm{CH}_{4}$ and can reach somewhat larger sizes for liquid separations $[4,19,20]$. Especially for liquid separations, permeation selectivities can also give information on micropore surface chemistries [4]. A combination of permeation and adsorption porosimetry is nanopermporometry. Nanopermporometry is commonly based on the Kelvin equation which should not be applied to pores $<2 \mathrm{~nm}$, but the technique has been reported to show reasonable correlation with membrane separation performance for pore sizes down to $0.5 \mathrm{~nm}$ [21]. Nanopermporometry can discriminate between hydrophilic and hydrophobic pore surfaces $[22,23]$, though for very small pores such distinctions are complicated by other effects [21]. A drawback of permeation porosimetry is that it requires the fabrication of defect-free membranes and the obtained information only represents a small part of the pore structure.

Adsorption porosimetry evaluates micropore characteristics on a larger scale via gaseous or liquid probe molecules that adsorb on the micropore surface. This adsorption is affected by the geometry of the micropore structure as well as the surface chemistry and analyzes all pores that are accessible to the probe molecules. Adsorption calorimetry [24,25] and temperature-programmed desorption measurements [26] provide information on surface chemistry. Gas adsorption isotherms provide more diverse information and are routinely obtained, e.g. for $\mathrm{N}_{2}$ at $-196{ }^{\circ} \mathrm{C}$ or $\mathrm{Ar}$ at $-186{ }^{\circ} \mathrm{C}$, to determine surface areas based on the BrunauerEmmett-Teller theory and determine pore volumes and sizes based on fitting to various models (e.g. non-local density functional theory, Saito-Foley, Dubinin-Radushkevich) [9,14,27-29]. For micropores approaching molecular dimensions, the gas mobility diminishes at cryogenic temperatures and $\mathrm{CO}_{2}$ adsorption at $0{ }^{\circ} \mathrm{C}$ can be used as alternative. The validity and limitations of gas adsorption isotherm analysis in the micropore regime have been discussed in literature extensively $[9,14,27-29]$. Adsorption isotherms of vapors (solvents) in microporous materials yield additional information on surface chemistry and can be obtained with e.g. ellipsometric porosimetry [30-32], though this method is not widely used. Furthermore, microporosity is occasionally revealed by adsorption isotherms of vapors in mesoporous materials obtained with X-ray reflection porosimetry [33] and quartz crystal microbalance porosimetry [34], indicating possibilities for these techniques to be developed further for microporous materials. As for analyzing micropore volumes, complete pore filling allows a more straightforward physical interpretation than partial pore filling, since no theoretical models on molecular behavior are needed for extrapolation. When using vapors instead of gases, complete pore filling can be achieved at room temperature and diffusion limitations due to cryogenic temperatures are thus eliminated. This more crude version of adsorption porosimetry (solvent-wall interactions are still highly relevant when filling pores of molecular dimensions) has been reported in literature for decades using gravimetry [2,35-38]. Despite its simplicity, (thermo)gravimetric porosimetry with vapors is not widely employed in materials research and engineering nowadays.

In the present study, the long known technique of vapor thermogravimetry (TG) is combined with a newly developed procedure for gas pycnometry (PM) to provide an experimental method for micropore analysis with improved accuracy in the size range $<1 \mathrm{~nm}$ as compared to conventional adsorption isotherms. Gas PM is generally used for density analysis, which in materials engineering tends to be done with He as probe gas because of its inertness and small size. Literature studies using PM in other fields, e.g. the coal, food and pharmaceutical industries, include other gases such as $\mathrm{N}_{2}$ and $\mathrm{H}_{2}[1,5-8]$ and occasionally revealed signs of gas adsorption in PM data [5,6]. In the present study, the use of PM to measure gas adsorption in porous materials is further developed. Firstly, vapor uptake in microporous materials is monitored with TG for direct and quantitative measurement of the accessible pore volume at room temperature. Information on micropore entrance sizes and surface chemistries is also obtained with vapor TG. Secondly, analyzing gas uptake in microporous materials with PM is shown to allow direct and semi-quantitative measurement of the surface-tovolume ratio and surface area at room temperature. Low degrees of pore filling are achieved with non-polar gases, eliminating the need for cryogenic temperatures and reducing complications due to confinement, surface curvature and enhanced adsorbent-adsorbate interactions. Information on surface chemistries is also obtained with gas PM. Thirdly, analyzing competitive uptake of multiple gases with PM allows probing of micropore cavity sizes separate from micropore entrances. Our analytical method is validated and calibrated by characterizing a series of zeolites with known micropore structures. Water, methanol, ethanol, 1-propanol and cyclohexane were used as vapor probe molecules for TG. Helium, argon and nitrogen were used as gas probe molecules for PM. The results are compared with data from conventional $\mathrm{N}_{2}$ adsorption isotherms at $-196{ }^{\circ} \mathrm{C}$ and $\mathrm{CO}_{2}$ adsorption isotherms at $0{ }^{\circ} \mathrm{C}$.

\section{Experimental}

\subsection{Chemicals}

Zeolite $\mathrm{A}$ in calcium form with $\mathrm{SiO}_{2}: \mathrm{Al}_{2} \mathrm{O}_{3}$ 2:1 (certification BCR$705,1-2 \%$ clay binder) was obtained from Sigma Aldrich. Zeolite ZSM5 in ammonium form with $\mathrm{SiO}_{2}: \mathrm{Al}_{2} \mathrm{O}_{3} 30: 1$, zeolite ZSM5 in ammonium form with $\mathrm{SiO}_{2}: \mathrm{Al}_{2} \mathrm{O}_{3}$ 200-400:1, zeolite $\beta$ in hydrogen form with $\mathrm{SiO}_{2}: \mathrm{Al}_{2} \mathrm{O}_{3} 360: 1$, zeolite $\mathrm{Y}$ in hydrogen form with $\mathrm{SiO}_{2}: \mathrm{Al}_{2} \mathrm{O}_{3}$ 5.1:1, zeolite $\mathrm{Y}$ in hydrogen form with $\mathrm{SiO}_{2}: \mathrm{Al}_{2} \mathrm{O}_{3}$ 80:1 and anhydrous methanol (purity 99.8\%, <0.005\% $\mathrm{H}_{2} \mathrm{O}$ ) were obtained from VWR. Anhydrous ethanol (purity 99.8\%, <0.01\% $\mathrm{H}_{2} \mathrm{O}$ ) was obtained from SeccoSolv. Anhydrous 1-propanol (purity 99.9\%) and cyclohexane (purity $>99 \%$ ) were obtained from Alfa Aesar.

\subsection{Sample preparation}

The millimeter-sized zeolite A pellets were ground with a mortar and pestle and then ball-milled to obtain powder. The ZSM5 zeolites in ammonium form were heated to $550{ }^{\circ} \mathrm{C}$ under $\mathrm{N}_{2}$ flow for $6 \mathrm{~h}$ (heating rate $450{ }^{\circ} \mathrm{C} \mathrm{h}^{-1}$ ) to obtain the hydrogen form [26].

\subsection{Thermogravimetry}

Thermogravimetric data was recorded with a Netzsch STA 449 F3 Jupiter machine and platinum crucibles. The sample was dried at $200{ }^{\circ} \mathrm{C}$ in synthetic air $\left(\mathrm{N}_{2}: \mathrm{O}_{2} 80: 20\right)$ for $4 \mathrm{~h}$, stabilized at $30{ }^{\circ} \mathrm{C}$ in synthetic air for $1 \mathrm{~h}$, filled with vapor at $30^{\circ} \mathrm{C}$ in humidified $\mathrm{N}_{2}$ for $18 \mathrm{~h}$, flushed at $30^{\circ} \mathrm{C}$ in synthetic air for $1 \mathrm{~h}$ and dried at $200{ }^{\circ} \mathrm{C}$ in synthetic air for $4 \mathrm{~h}$. Heating and cooling rates were $5^{\circ} \mathrm{C} \mathrm{min}^{-1}$. The supplied gases were dried with SGE packed column moisture traps and the $\mathrm{N}_{2}$ was subsequently humidified by bubbling through a solvent at room temperature $(40 \mathrm{~mL}$, bubble path length approximately $12 \mathrm{~cm}$ ). The relative vapor pressure was assumed to reach the saturation value at room temperature and remain slightly below the saturation value at $30^{\circ} \mathrm{C}$, reducing the risk on unwanted 
condensation during the measurement. The gas flow rate was $60 \mathrm{~mL} \mathrm{~min}^{-1}$ and data were recorded every $10 \mathrm{~s}$.

\subsection{Pycnometry}

Pycnometry measurements were done with a Quantachrome Instruments Multipycnometer in the microcell configuration and gases of $>99.999 \%$ purity ( $\mathrm{He}, \mathrm{Ar})$ and $>99.996 \%$ purity $\left(\mathrm{N}_{2}\right)$ that were led through an SGE packed column moisture trap before entering the pycnometer. The sample was loaded in the sample cell and then dried in an oven at $150{ }^{\circ} \mathrm{C}$ under $\mathrm{N}_{2}$ flow for $3 \mathrm{~h}$. Immediately afterwards, the sample was weighed and loaded in the pycnometer. The apparent sample volume was analyzed with $\mathrm{He}$ $\mathrm{He}+\mathrm{He}, \mathrm{He}+\mathrm{N}_{2}, \mathrm{Ar}, \mathrm{N}_{2}$ and $\mathrm{N}_{2}+\mathrm{N}_{2}$ (measured in this order). For the measurements with a single gas, approximately $0.30 \mathrm{mmol}$ gas was added $\left(\Delta p_{\text {ref }} \approx 1.2 \times 10^{5} \mathrm{~Pa}\right.$ ) and the cell pressure was monitored for $10 \mathrm{~min}$. The cell was then slowly vented to atmospheric pressure in approximately $1 \mathrm{~min}$ and the next measurement was started immediately afterwards (for adsorbing gases the desorption time may affect the subsequent adsorbing amount and should be kept constant). This was repeated until the system was equilibrated and yielded consistent results for three consecutive runs. For the measurements with two gases, $0.15 \mathrm{mmol}$ of the first gas was added $\left(\Delta p_{\text {ref }} \approx 6 \times 10^{4} \mathrm{~Pa}\right)$, then the cell pressure was monitored for $10 \mathrm{~min}$, then $0.15 \mathrm{mmol}$ of the second gas was added $\left(\Delta p_{\text {ref }} \approx 6 \times 10^{4} \mathrm{~Pa}\right)$ and the cell pressure was monitored again for $10 \mathrm{~min}$.

\subsection{Adsorption isotherms}

Adsorption isotherms were collected with a Quantachrome Instruments Autosorb-1 and the gases were led through a moisture trap before entering the set-up. The sample was outgassed at $300{ }^{\circ} \mathrm{C}$ for $3 \mathrm{~h}$. Adsorption isotherms were collected for $\mathrm{CO}_{2}$ at $0{ }^{\circ} \mathrm{C}$ and for $\mathrm{N}_{2}$ at $-196{ }^{\circ} \mathrm{C}$. Brunauer-Emmett-Teller (BET) curves derived from $\mathrm{CO}_{2}$ adsorption were based on at least 4 data points.

\section{Results and discussion}

A list of variables used in this study is given in Table 1. Structural information of the used zeolites is listed in Table 2, including the average tetrahedral unit molecular weight $m_{\mathrm{T}}$, theoretical framework density $\rho_{\mathrm{fr}, \mathrm{th}}$, theoretical accessible volume $V_{\mathrm{acc}, \mathrm{th}}$, theoretical accessible surface area $A_{\mathrm{acc}, \text { th }}$ and maximum sphere size $d$ that can be included in or pass through the micropores. The framework density (envelope density) includes both the skeleton and the pores. A schematic representation of the vapor TG and gas PM experiments and definitions of various parameters is shown in Fig. 1. The accessible volume as listed in the Database of Zeolite Structures [39] is defined as the pore volume that can be reached by the center of a hard sphere with a radius of $1.4 \AA$, thus excluding the regions within $1.4 \AA$ from the pore surface and systematically underestimating the real accessible volume to a large extent. No accurate volume estimations could be obtained mathematically due to the complexity of the pore structures. The accessible surface area as listed in the Database of Zeolite Structures [39] is defined as the surface area that can be covered by the center of a hard sphere with a radius of $1.4 \AA$, thus also underestimating the real accessible surface area.

\subsection{Vapor TG and He PM}

Vapor TG measurements were done to measure the accessible pore volume of the zeolites for water, methanol, ethanol, 1propanol and cyclohexane. The samples were dried in-situ at
$200{ }^{\circ} \mathrm{C}$ and then exposed to a flow of $\mathrm{N}_{2}$ with one of the vapors at $30{ }^{\circ} \mathrm{C}$ for $18 \mathrm{~h}$. The mass uptake was divided by the bulk liquid density to estimate the uptake in volume, though the solvents do not necessarily maintain their bulk densities inside the micropores due to the small micropore sizes and significant wall-solvent interactions. Dehydrated alcohols were used and the carrier gases were led through a moisture trap before entering the set-up, but reference measurements with dried gases indicated that traces of water were still present in the gases after drying. This may have caused an overestimation of the organic solvent uptake by a few percent. Results are shown in Fig. 2. For most samples no significant differences were observed between the total uptake of methanol, ethanol, 1-propanol and cyclohexane, indicating that all micropore structures were accessible to all molecules and indicating no significant interparticle adsorption (interparticle adsorption is expected to scale with vapor volatility). Only the hydrophobic zeolites $\mathrm{H}-\mathrm{Y}_{80}$ and to a lesser extent H-ZSM5 300 showed, unlike their hydrophilic counterparts, a slightly decreasing vapor uptake in the order ethanol $>$ methanol $\approx 1$-propanol $>$ cyclohexane. This can be explained by larger molecules leaving larger packing voids (which may have been filled with traces of water from the carrier gases in the hydrophilic structures) and methanol showing hindered uptake because of its high polarity. For most samples the water uptake was significantly lower than the organic solvent uptake and the uptake decreased with increasing $\mathrm{SiO}_{2}: \mathrm{Al}_{2} \mathrm{O}_{3}$ ratio (increasing hydrophobicity). Water/methanol uptake ratios are listed in Table 3 to facilitate comparison, though it should be kept in mind that the influence of surface chemistry on vapor uptake increases with the surface-to-volume ratio. Simultaneous differential scanning calorimetry monitoring (data not shown) indicated that alcoholic pore filling was increasingly exothermic for increasing micropore hydrophilicity, likely due to the formation of hydrogen bonds between solvent and zeolite. All zeolites showed rapid filling by all vapors and an increasing filling rate with increasing vapor pressure. No dependency on micropore size was observed.

The accessible pore volume $V_{\text {acc,TG }}$ of each sample was taken as the average of the methanol, ethanol and 1-propanol uptakes. The results are listed in Table 3 together with PM data. PM measurements with $\mathrm{He}$ as probe gas were done to obtain a second experimental value for the accessible pore volume, $V_{\text {acc,He, and the } \mathrm{He}}$ density $\rho_{\mathrm{He}}$. $V_{\mathrm{acc}, \mathrm{He}}$ was obtained by subtracting the sample volume as measured with He from the sample framework volume as derived from the sample mass and the theoretical framework density $\rho_{\mathrm{fr}, \mathrm{th}}$. An experimental value for the framework volume, $V_{\mathrm{fr}}$, was derived from $V_{\mathrm{acc}, \mathrm{TG}}$ and $\rho_{\mathrm{He}}$ to further check the validity of the data. The theoretical accessible volume $V_{\text {acc,th }}$, theoretical skeletal density $\rho_{\text {sk,th }}$ and theoretical framework volume $V_{\text {fr,th }}$ are added in Table 3 as references. As mentioned above, the accessible volume as listed in the Database of Zeolite Structures [39] systematically underestimates both the real accessible volume and the skeletal density to a large extent. Indeed, $V_{\text {acc,TG }}$ and $V_{\text {acc,He }}$ are significantly larger than $V_{\mathrm{acc}, \text { th }}$, and $\rho_{\mathrm{He}}$ is significantly larger than $\rho_{\mathrm{sk}, \text { th }}$ for zeolites H-ZSM5, $\mathrm{H}-\mathrm{B}$ and $\mathrm{H}-\mathrm{Y}$. The values of $V_{\text {acc,TG }}$ and $V_{\text {acc,He }}$ correspond reasonably for these zeolites, indicating no gas pressure build-up due to confinement in narrow pores (for interactions of gas molecules with the pore walls becoming increasingly dominant over collisions between neighboring gas molecules, the effective pressure is ultimately expected to decrease and cause a net pressure build-up). For zeolite Ca- $\mathrm{A}_{2}, V_{\text {acc,TG }}$ is not larger than $V_{\text {acc,th }}$ and is only half of $V_{\text {acc,He}}$. This suggests that $V_{\text {acc,TG }}$ is an underestimation, possibly due to poor packing of vapor molecules in the narrowest parts of the pore structure. As for the framework volumes, for zeolite $\mathrm{Ca}-\mathrm{A}_{2}$ the expected underestimation in $V_{\mathrm{acc}, \mathrm{TG}}$ also yields an underestimation in $V_{\mathrm{fr}}$. For the other zeolites $V_{\mathrm{fr}}$ and $V_{\mathrm{fr}, \text { th }}$ correspond reasonably. This further confirms the reliability of the 
Table 1

List of variables.

\begin{tabular}{|c|c|}
\hline symbol & definition \\
\hline$A_{\mathrm{acc}}$ & accessible surface area \\
\hline$A_{\text {acc,th }}$ & theoretical accessible surface area \\
\hline$A_{\mathrm{acc}, \mathrm{th}} / V_{\mathrm{acc}, \mathrm{th}}$ & theoretical surface-to-volume ratio \\
\hline$A_{\mathrm{BET}, \mathrm{CO} 2}$ & BET surface area as derived from $\mathrm{CO}_{2}$ adsorption \\
\hline$\alpha$ & selectivity \\
\hline$c$ & BET constant \\
\hline$d_{\text {included }}$ & theoretical maximum sphere size that can be included in the pores (pore cavity size) \\
\hline$d_{\text {passing }}$ & theoretical maximum sphere size that can pass through the pores (pore entrance size) \\
\hline$m_{\mathrm{T}}$ & average molecular weight of zeolite tetrahedral unit \\
\hline$\Delta N$ & amount of added gas \\
\hline$\Delta N_{\mathrm{c}}$ & amount of added gas located outside the sample framework \\
\hline$\Delta N_{\mathrm{fr}}$ & amount of added gas located inside the sample framework \\
\hline$\Delta N_{\mathrm{B} \rightarrow \mathrm{A}}$ & amount of gas B added to a background of gas $\mathrm{A}$ \\
\hline$\Delta N_{\mathrm{c}, \mathrm{B} \rightarrow \mathrm{A}}$ & amount of gas B added to a background of gas A and located outside the sample framework \\
\hline$\Delta N_{\mathrm{fr}, \mathrm{B} \rightarrow \mathrm{A}}$ & amount of gas B added to a background of gas A and located inside the sample framework \\
\hline$\Delta p_{\text {acc }}$ & change in 'apparent pressure' of probe molecules inside the accessible pore volume \\
\hline$\Delta p_{\mathrm{c}}$ & cell pressure difference \\
\hline$\Delta p_{\text {acc }} / \Delta p_{\mathrm{c}}$ & gas accumulation factor \\
\hline$p / p_{0}$ & relative pressure \\
\hline$\rho_{\mathrm{fr}, \mathrm{th}}$ & theoretical framework density (skeleton + pores) \\
\hline$\rho_{\mathrm{He}}$ & skeletal density as measured with He PM \\
\hline$\rho_{\text {sk,th }}$ & theoretical skeletal density \\
\hline$r$ & BET correlation coefficient \\
\hline$t$ & time \\
\hline$V_{\mathrm{c}}$ & calibrated cell volume \\
\hline$V_{\text {acc,th }}$ & theoretical accessible volume \\
\hline$V_{\mathrm{acc}, \mathrm{He}}$ & accessible volume as measured with He PM \\
\hline$V_{\text {acc,TG }}$ & accessible volume as measured with vapor TG \\
\hline$V_{\mathrm{fr}}$ & framework volume (skeleton + pores) as measured with He PM and vapor TG \\
\hline$V_{\mathrm{fr}, \mathrm{th}}$ & theoretical framework volume \\
\hline
\end{tabular}

\section{Table 2}

Framework type, average tetrahedral unit molecular weight $m_{\mathrm{T}}$, theoretical framework density $\rho_{\mathrm{fr}, \text { th }}$, theoretical accessible volume $V_{\text {acc,th }}$, theoretical accessible surface area $A_{\text {acc,th }}$, maximum sphere size that can be included in the pores $d_{\text {included }}$ and maximum sphere size that can pass through the pores $d_{\text {passing }}$ of the zeolites used in this study.

\begin{tabular}{|c|c|c|c|c|c|c|}
\hline sample & $\mathrm{Ca}-\mathrm{A}_{2}$ & H-ZSM5 30 & H-ZSM5 300 & $\mathrm{H}-\mathrm{B}_{360}$ & $H-Y_{5.1}$ & $\mathrm{H}-\mathrm{Y}_{80}$ \\
\hline $\mathrm{SiO}_{2}: \mathrm{Al}_{2} \mathrm{O}_{3}$ & $2: 1$ & $30: 1$ & $200-400: 1$ & $360: 1$ & $5.1: 1$ & $80: 1$ \\
\hline framework type & LTA & MFI & MFI & *BEA & FAU & FAU \\
\hline$m_{\mathrm{T}}\left[\mathrm{g} \mathrm{mol}^{-1}\right]$ & 55.53 & 59.52 & 60.02 & 60.03 & 57.52 & 59.86 \\
\hline$\rho_{\mathrm{fr}, \mathrm{th}}{ }^{\mathrm{a}}\left[\mathrm{T} \mathrm{nm}^{-3}\right]$ [39] & 14.2 & 18.4 & 18.4 & 15.3 & 13.3 & 13.3 \\
\hline$\rho_{\mathrm{fr}, \mathrm{th}}\left[\mathrm{g} \mathrm{cm}^{-3}\right]$ & 1.31 & 1.82 & 1.83 & 1.53 & 1.27 & 1.32 \\
\hline$V_{\text {acc,th }}[\%][39]$ & 21.4 & 9.81 & 9.81 & 20.52 & 27.42 & 27.42 \\
\hline$A_{\text {acc,th }}\left[\mathrm{m}^{2} \mathrm{~g}^{-1}\right][39]$ & 1205 & 834 & 834 & 1220 & 1211 & 1211 \\
\hline$d_{\text {included }}[\AA ̊][39]$ & 11.05 & 6.36 & 6.36 & 6.68 & 11.24 & 11.24 \\
\hline$d_{\text {passing }}[\AA][39]$ & 4.21 & $4.7 \& 4.46$ & $4.7 \& 4.46$ & 5.95 & 7.35 & 7.35 \\
\hline
\end{tabular}

a Assuming a composition of $100 \% \mathrm{SiO}_{2}$.

analytical method. The He cell pressure stabilized well within the measurement time for all zeolites, indicating no size hinder via slow diffusion. Recalculation of the PM results with calibration shifts as observed throughout the measurements and with duplicate measurements yielded only minor deviations (within 1 digit or $5 \%)$.

The results above demonstrate that vapor TG can be used to directly determine quantitative accessible micropore volumes at room temperature based on pore filling from approximately zero to $100 \%$ of the pore volume. This makes it a robust method that eliminates the need for theoretical models on molecular behavior to extrapolate from partial pore filling, though errors from deviations in packing density cannot be fully excluded. Comparing the uptake of polar and non-polar vapors indicates differences in micropore surface chemistries and the accessibility to molecules with specific molecular sizes gives information on pore entrance sizes. With He PM the accessible pore volume can only be calculated if the framework volume (skeleton + pores) of the sample is known.

\subsection{Ar and $N_{2} P M$}

PM measurements with $\mathrm{Ar}$ and $\mathrm{N}_{2}$ as probe gases were done to measure the uptake of molecules that are more polarizable than $\mathrm{He}$ and extract information on the surface-to-volume ratio and surface area of the samples. The sample framework volume $V_{\mathrm{fr}}$ (volume of skeleton + pores) present in the measurement cell can be derived from the sample mass, accessible volume $V_{\text {acc,TG }}$ and He density $\rho_{\mathrm{He}}$. The ideal gas law, calibrated cell volume $V_{c}$, amount of added gas $\Delta N$ and resulting cell pressure difference $\Delta p_{c}$ can then be used to calculate the amount of added gas located outside the sample framework $\Delta N_{\mathrm{c}}$ and the amount of added gas located inside the sample framework $\Delta N_{\mathrm{fr}}$ according to

$\Delta N_{c}=\frac{\Delta p_{c} \cdot\left(V_{c}-V_{f r}\right)}{R T}$

$\Delta N_{f r}=\Delta N-\Delta N_{c}$

with $\Delta N_{\mathrm{x}}$ in mole, $\Delta p_{\mathrm{c}}$ in $\mathrm{Pa}, V_{\mathrm{x}}$ in $\mathrm{m}^{3}$, the ideal gas constant $R$ (8.314 $\mathrm{J} \mathrm{K}^{-1} \mathrm{~mol}^{-1}$ ) and the temperature $T$ in K. Now $\Delta N_{\mathrm{fr}}$ can be expressed as a change in concentration or 'apparent pressure' of probe molecules inside the accessible pore volume, $\Delta p_{\text {acc }}$, based on $V_{\text {acc,TG }}$ and the ideal gas law. The ratio of $\Delta p_{\text {acc }}$ over the pressure change outside the sample, $\Delta p_{c}$, yields a dimensionless gas accumulation factor $\Delta p_{\text {acc }} / \Delta p_{\mathrm{c}}$. Note that $\Delta p_{\text {acc }}$ is only a measure for the number of probe molecules per unit pore volume and does not consider their physical state as free or adsorbed gas. The gas uptake inside the sample is assumed not to be limited by gas depletion outside the sample. 
a)

1 vapor

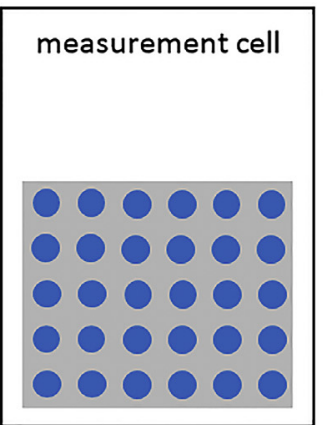

○
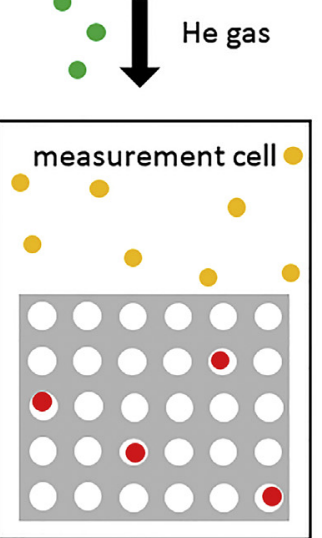

○
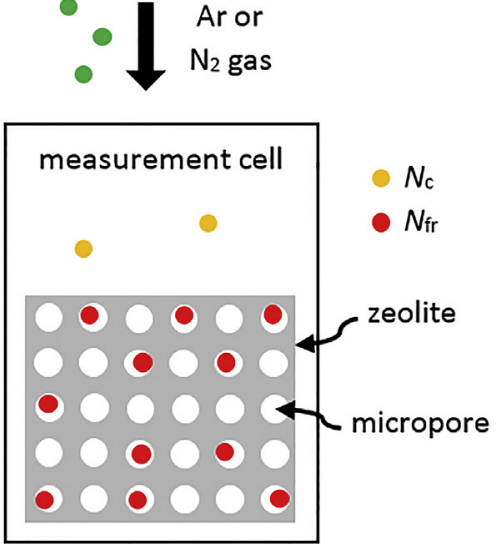

b)

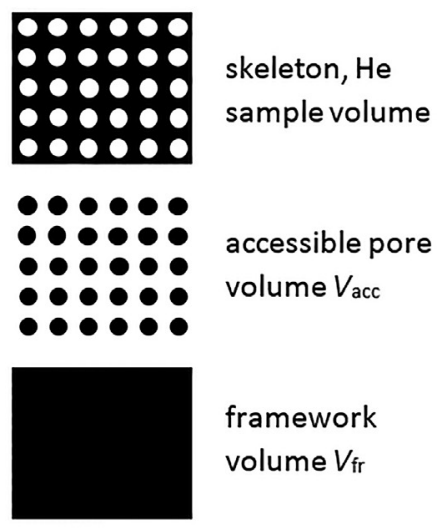

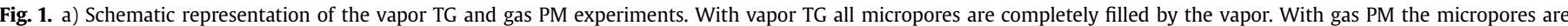

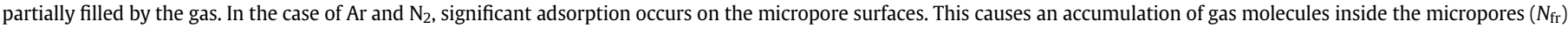
as compared to gas molecules outside the sample $\left(N_{c}\right)$. b) Schematic definition of the zeolite skeleton volume, pore volume and framework volume.

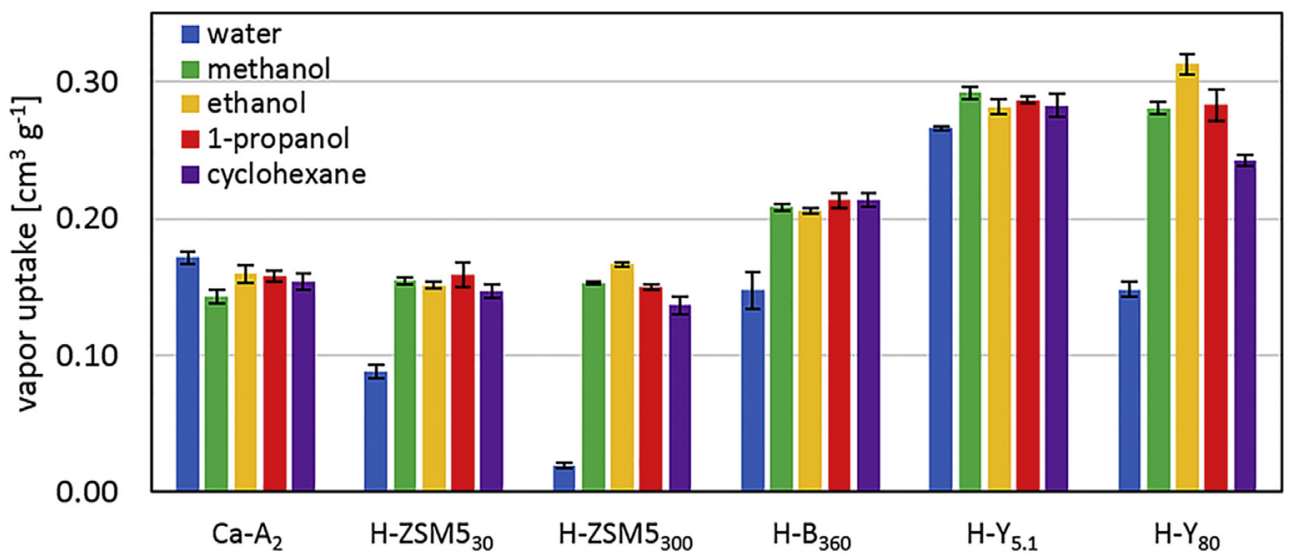

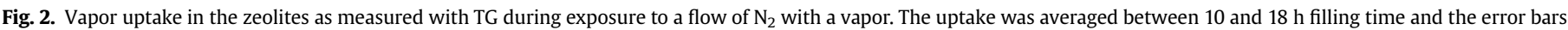
indicate two times the standard deviation.

Table 3

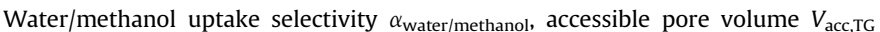
based on vapor TG, accessible pore volume $V_{\text {acc.He }}$ based on He PM, theoretical accessible pore volume $V_{\text {acc,th }}$, He density $\rho_{\mathrm{He}}$, theoretical skeletal density $\rho_{\mathrm{sk}, \mathrm{th}}$, sample framework volume $V_{\mathrm{fr}}$ based on He PM and vapor TG and theoretical framework volume $V_{\mathrm{fr}, \text { th }}$ of the zeolites. The error in vapor TG data is within 1 digit (two times the standard deviation). The error in He PM data is within 1 digit or $5 \%$.

\begin{tabular}{|c|c|c|c|c|c|c|}
\hline sample & Ca- $\mathrm{A}_{2}$ & $\mathrm{H}-\mathrm{ZSM} 5_{30}$ & $\mathrm{H}^{-Z S M} 5_{300}$ & $\mathrm{H}-\mathrm{B}_{360}$ & $H-Y_{5.1}$ & $\mathrm{H}-\mathrm{Y}_{80}$ \\
\hline$\alpha_{\text {water/methanol }}[-]$ & 1.2 & 0.6 & 0.1 & 0.7 & 0.9 & 0.5 \\
\hline$V_{\mathrm{acc}, \mathrm{TG}}\left[\mathrm{cm}^{3} \mathrm{~g}^{-1}\right]$ & 0.15 & 0.15 & 0.16 & 0.21 & 0.29 & 0.29 \\
\hline$V_{\mathrm{acc}, \mathrm{He}}\left[\mathrm{cm}^{3} \mathrm{~g}^{-1}\right]$ & 0.31 & 0.12 & 0.13 & 0.21 & 0.35 & 0.32 \\
\hline$V_{\text {acc,th }}\left[\mathrm{cm}^{3} \mathrm{~g}^{-1}\right]$ & 0.16 & 0.05 & 0.05 & 0.13 & 0.22 & 0.21 \\
\hline$\rho_{\mathrm{He}}\left[\mathrm{g} \mathrm{cm}^{-3}\right]$ & 2.2 & 2.3 & 2.4 & 2.2 & 2.3 & 2.3 \\
\hline$\rho_{\text {sk,th }}\left[\mathrm{g} \mathrm{cm}^{-3}\right]$ & 1.7 & 2.0 & 2.0 & 1.9 & 1.8 & 1.8 \\
\hline$V_{\mathrm{fr}}\left[\mathrm{cm}^{3} \mathrm{~g}^{-1}\right]$ & 0.61 & 0.59 & 0.58 & 0.66 & 0.72 & 0.73 \\
\hline$V_{\mathrm{fr}, \mathrm{th}}\left[\mathrm{cm}^{3} \mathrm{~g}^{-1}\right]$ & 0.76 & 0.55 & 0.55 & 0.66 & 0.79 & 0.76 \\
\hline
\end{tabular}

Results are listed in Table 4. Though cell pressure stabilization took longer for $\mathrm{Ar}$ and $\mathrm{N}_{2}$ than for $\mathrm{He}$, equilibrium was approached within the measurement time for all zeolites. The uptake of Ar and $\mathrm{N}_{2}$ is much larger than the uptake of He for all zeolites, which indicates adsorption of $\mathrm{Ar}$ and $\mathrm{N}_{2}$ on the pore surfaces. The highest absolute gas concentration inside the micropores was the equivalent of about 34 bar $\left(\mathrm{N}_{2}\right.$ in $\mathrm{H}-\mathrm{ZSM} 5_{300}$ based on $\left.V_{\mathrm{acc}, \mathrm{TG}}, p_{\mathrm{c}} \approx 1.3 \mathrm{bar}\right)$, i.e. the pressure would be 34 bar if all molecules existed as free gas rather than being adsorbed. This corresponds with about $2 \%$ of the pore volume being occupied by $\mathrm{N}_{2}$ molecules. Converting this to the number of pore cavities per $\mathrm{N}_{2}$ yields more than 8 cavities per molecule $\left(V_{\mathrm{N} 2} \approx 25 \AA^{3}, V_{\text {cavity }} \approx 135 \AA^{3}\right)$. For such low gas concentrations no significant multilayer adsorption or curvaturerelated packing problems due to crowded monolayers are expected. The gas accumulation factor of $\mathrm{He}, \mathrm{Ar}$ and $\mathrm{N}_{2}$ is plotted against the theoretical surface-to-volume ratio $A_{\text {acc,th }} / V_{\text {acc,th }}$ in Fig. 3. Though both $A_{\mathrm{acc}, \text { th }}$ and $V_{\mathrm{acc}, \text { th }}$ significantly underestimate the reality, their errors are related and are assumed to compensate each other. For monolayer-like adsorption with low coverage a linear relation is expected between the gas accumulation factor and the surface-to-volume ratio and this is indeed observed for zeolites $\mathrm{H}$ ZSM5, H-B and H-Y, suggesting reasonable accuracy. The uptake of $\mathrm{Ar}$ and $\mathrm{N}_{2}$ per unit surface-to-volume in zeolite $\mathrm{Ca}-\mathrm{A}_{2}$ was lower in comparison with the other zeolites, which can be explained by the measurement conditions. Ar and $\mathrm{N}_{2}$ uptake in zeolite $\mathrm{Ca}-\mathrm{A}_{2}$ reached approximately $80 \%$ of the end value in $1 \mathrm{~min}$ (in contrast to $97-100 \%$ for the other zeolites). This indicates that the venting time between measurements, which was set to approximately $1 \mathrm{~min}$, did not allow fully equilibrated desorption. The subsequently measured uptake values thus underestimated the adsorption capacity. Increasing the venting time to $10 \mathrm{~min}$ increased $\Delta p_{\text {acc }} / \Delta p_{\mathrm{c}}$ to 5.2 for $\mathrm{N}_{2}$ in zeolite $\mathrm{Ca}-\mathrm{A}_{2}$, though now the uptake did not equilibrate 
Table 4

Gas accumulation factor $\Delta p_{\text {acc }} / \Delta p_{c}$, accessible surface area $A_{\text {acc }}$ and selectivity $\alpha$ for He, $\operatorname{Ar}$ and $N_{2}$ uptake in the zeolites.

\begin{tabular}{|c|c|c|c|c|c|c|c|}
\hline zeolite & & $\mathrm{Ca}-\mathrm{A}_{2}$ & $\mathrm{H}_{-\mathrm{ZSM}} 5_{30}$ & H-ZSM5 300 & $\mathrm{H}-\mathrm{B}_{360}$ & $\mathrm{H}-\mathrm{Y}_{5.1}$ & $\mathrm{H}-\mathrm{Y}_{80}$ \\
\hline \multirow[t]{3}{*}{$\Delta p_{\text {acc }} / \Delta p_{\mathrm{c}}[-]$} & $\mathrm{He}$ & 1.0 & 1.0 & 1.0 & 1.0 & 1.0 & 1.0 \\
\hline & $\mathrm{Ar}$ & 3.5 & 23.8 & 26.0 & 13.8 & 7.3 & 7.3 \\
\hline & $\mathrm{N}_{2}$ & 3.5 & 25.1 & 26.4 & 14.3 & 8.5 & 7.5 \\
\hline$A_{\mathrm{acc}}\left[\mathrm{m}^{2} \mathrm{~g}^{-1}\right]$ & $\mathrm{Ar}$ & 539 & 2291 & 2507 & 1928 & 1612 & 1652 \\
\hline$\alpha_{\mathrm{N} 2 / \mathrm{Ar}}[-]$ & & 1.0 & 1.1 & 1.0 & 1.0 & 1.2 & 1.0 \\
\hline
\end{tabular}

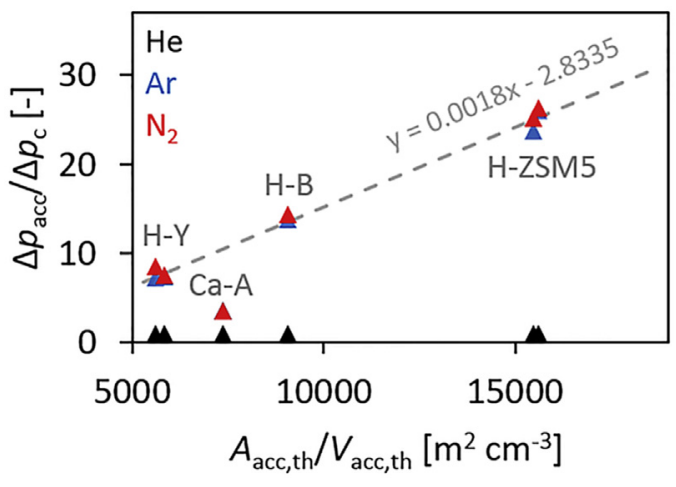

Fig. 3. Gas accumulation of $\mathrm{He}, \mathrm{Ar}$ and $\mathrm{N}_{2}$ in the zeolite pore structures plotted against their theoretical surface-to-volume ratios. The trend line is based on the data of $\mathrm{Ar}$ excluding Ca-A.

anymore within 10 min measurement time, still yielding an underestimation. The slow adsorption and desorption kinetics in zeolite $\mathrm{Ca}-\mathrm{A}_{2}$ may be due to its very small pore entrance size. Another important factor is particle size (diffusion path lengths); scanning electron microscopy imaging of the powders (data not shown) indicated that zeolite $\mathrm{Ca}-\mathrm{A}_{2}$ was the only sample containing a significant number of particles $>3 \mu \mathrm{m}$.

The trend line in Fig. 3 can be used as semi-quantitative calibration for unknown samples, provided that similar measurement conditions are applied and the micropores are not too small. From the trend line and $V_{\text {acc,TG }}$ the accessible surface area $A_{\text {acc }}$ was derived, as expected indicating significantly larger surface areas for zeolites H-ZSM5, H-B and $\mathrm{H}-\mathrm{Y}$ than the underestimated theoretical values in Table 2 suggest. $A_{\text {acc }}$ being lower than $A_{\text {acc,th }}$ for zeolite Ca$\mathrm{A}_{2}$ can be explained with the previously discussed underestimations in both $V_{\text {acc,TG }}$ and the uptake of Ar. For zeolites HZSM5 and $\mathrm{H}-\mathrm{Y}$ the $\mathrm{N}_{2} / \mathrm{Ar}$ selectivity $\alpha_{\mathrm{N} 2 / \mathrm{Ar}}$ increased with increasing hydrophilicity. This corresponds with $\mathrm{N}_{2}$ having a quadrupolar moment and a higher electric polarizability than Ar [40], which makes $\mathrm{N}_{2}$ more sensitive to polar adsorption sites.

PM measurements with competitive gas filling were done to obtain more information on the micropore cavity dimensions. When filling a micropore structure with a single type of probe molecules, equilibrium can be reached without probe molecules needing to pass each other inside the pore structure and the filling rate is mostly determined at the pore entrances (bottlenecks). When a micropore structure is filled with gas $A$ and then filled further with another gas $B$, molecules of $A$ and $B$ have to pass each other inside the pores in order to mix and reach equilibrium. Since passing of molecules will occur mostly at the widest positions in the pores, the equilibration rate of gas $B$ depends mostly on the cavity size in between the bottlenecks and much less on the size of the pore entrances. Comparing the equilibration behavior of gas $\mathrm{B}$ added to a background of gas $A$ with the equilibration behavior of gas $B$ added to a background of gas $B$ thus provides information specifically on the cavity size. When adding an amount $\Delta N_{\mathrm{B} \rightarrow \mathrm{A}}$ of gas $\mathrm{B}$ to a background of gas $\mathrm{A}$ ( or $\mathrm{B}$ ), at time $t=0$ all added gas is in
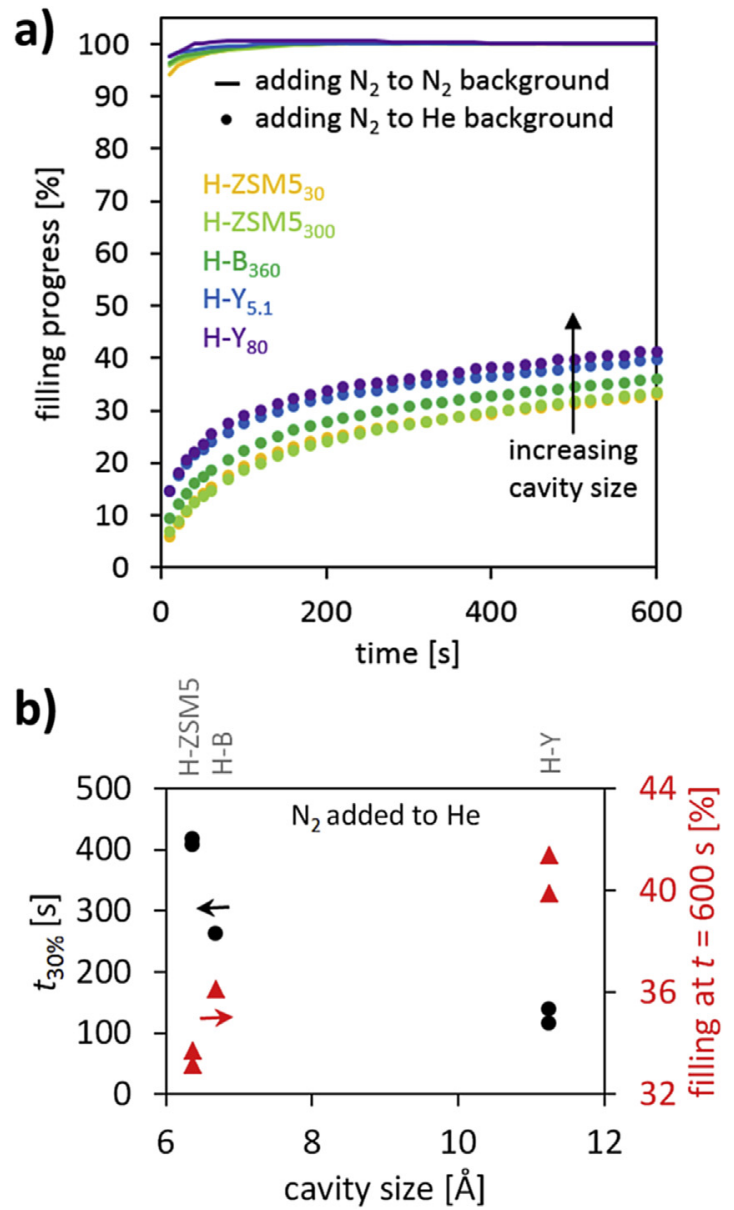

Fig. 4. a) Pore filling curves for $\mathrm{N}_{2}$ added to a background of $\mathrm{N}_{2}$ (solid curves) and for $\mathrm{N}_{2}$ added to a background of He (dotted curves) for zeolites H-ZSM5, H-B and H-Y. b) Time at $30 \%$ filling and filling at $t=600 \mathrm{~s}$ for $\mathrm{N}_{2}$ added to a background of He in zeolites H-ZSM5, H-B and H-Y, plotted against the micropore cavity sizes.

the cell outside the sample, yielding $\Delta N_{\mathrm{c}, \mathrm{B} \rightarrow \mathrm{A}}(0)=\Delta N_{\mathrm{B} \rightarrow \mathrm{A}}$ and $\Delta N_{\mathrm{fr}, \mathrm{B} \rightarrow \mathrm{A}}(0)=0$. With progressing time gas $\mathrm{B}$ diffuses into the sample and $\Delta N_{\mathrm{c}, \mathrm{B} \rightarrow \mathrm{A}}(t)$ and $\Delta N_{\mathrm{fr}, \mathrm{B} \rightarrow \mathrm{A}}(t)$ can be calculated as a function of the changing cell pressure difference $\Delta p_{c}(t)$ with Equations (1) and (2). The equilibrium uptake of gas $B$ inside the sample is $\Delta N_{\mathrm{fr}, \mathrm{B} \rightarrow \mathrm{B}}(\infty) / \Delta N_{\mathrm{B} \rightarrow \mathrm{B}}$ for gas B being added to a background of gas $B$. Now the filling progress in time of gas $B$ being added to a background of gas A (or B) can be calculated by

filling progress $(t)=\frac{\Delta N_{f r, \mathrm{~B} \rightarrow \mathrm{A}}(t)}{\frac{\Delta N_{f r, \mathrm{~B} \rightarrow \mathrm{B}}(\infty)}{\Delta N_{\mathrm{B} \rightarrow \mathrm{B}}} \cdot \Delta N_{\mathrm{B} \rightarrow \mathrm{A}}} \cdot 100 \%$

Monitoring mixing behavior is facilitated by choosing an adsorbing species as gas $B$ to create a large flux into the sample. A nonadsorbing species is preferred as gas $A$ to minimize temporary 

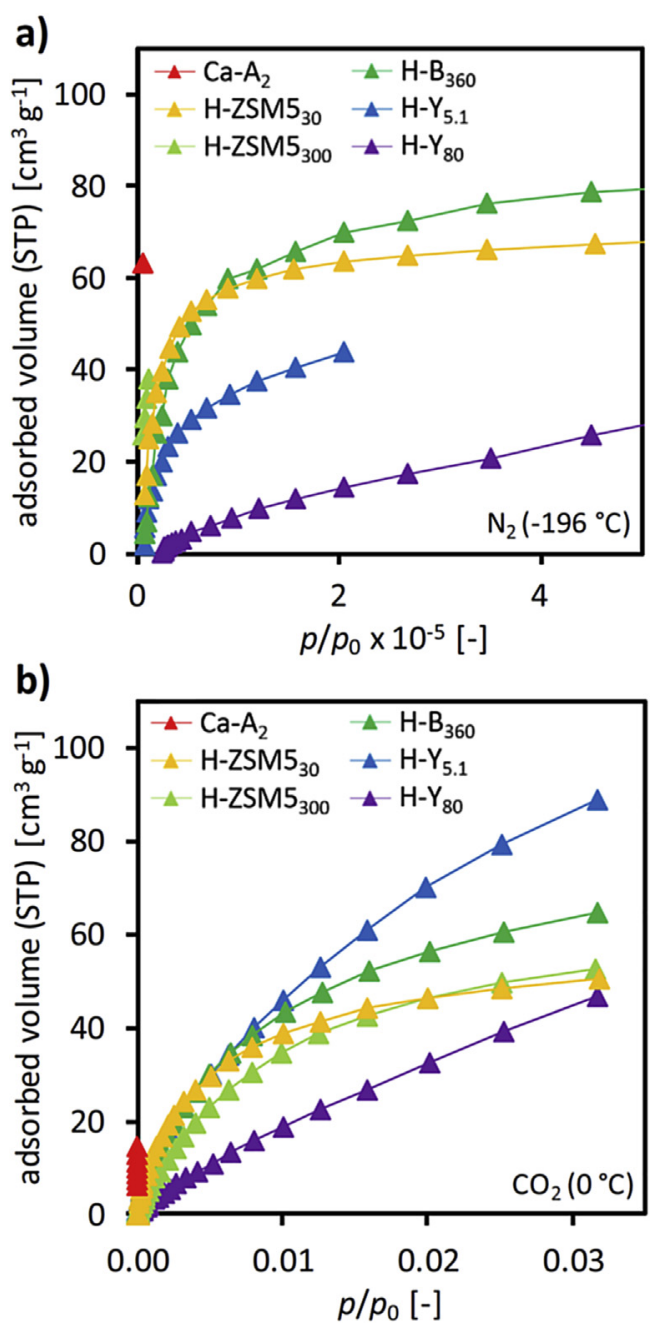

Fig. 5. a) $\mathrm{N}_{2}$ adsorption isotherms at $-196{ }^{\circ} \mathrm{C}$ and b) $\mathrm{CO}_{2}$ adsorption isotherms at $0{ }^{\circ} \mathrm{C}$ of the zeolites.

excess uptake of gas $A$ in the first stage of increased cell pressure before gas $B$ has reached the sample.

Fig. 4a shows the filling progress in time after the addition of $\mathrm{N}_{2}$ to a background of either $\mathrm{N}_{2}$ or He for zeolites H-ZSM5, H-B and $\mathrm{H}-$ $\mathrm{Y}$. For $\mathrm{N}_{2}$ being added to a background of $\mathrm{N}_{2}$ (solid curves) the cell pressure equilibrated equally rapid, indicating no effect of variations in the pore entrance size on the diffusion of $\mathrm{N}_{2}$ into these samples. Data of zeolite $\mathrm{Ca}-\mathrm{A}_{2}$ are excluded because the cell pressure did not stabilize within the measurement time, providing no suitable reference point for further calculations. For $\mathrm{N}_{2}$ being added to a background of $\mathrm{He}$ (dotted curves) the cell pressure equilibrated significantly slower, indicating that mixing of $\mathrm{N}_{2}$ and He inside the pore structures was hindered. The filling rates followed the order in micropore cavity size H-ZSM5 (d $d_{\text {included }}=6.36 \AA$ ) $<\mathrm{H}-\mathrm{B}$ $\left(d_{\text {included }}=6.68 \AA\right)<H-Y\left(d_{\text {included }}=11.24 \AA\right)$. Fig. $4 \mathrm{~b}$ shows the time it takes to reach 30\% filling and the achieved filling at $t=600 \mathrm{~s}$ plotted against the micropore cavity sizes.

The results above demonstrate that PM with various gases can be used to probe surface-to-volume ratios, surface areas and micropore cavity sizes. The observed relations between the gas accumulation factor and the surface-to-volume ratio in Fig. 3 and between the competitive filling rate and micropore cavity size in Fig. 4b can be used as semi-quantitative calibration for unknown samples. The data also shows some differentiation between pore chemistries. The demonstrated approach is expected to be valid for micropore structures with entrance sizes down to about $0.45 \mathrm{~nm}$ when using $\mathrm{Ar}$ and $\mathrm{N}_{2}$ as probe gases, though smaller probe molecules and longer equilibration times may enable analysis of even smaller pores. Larger probe molecules that only barely have access to the pores hinder the measurements due to very slow equilibration and the same holds for strongly adsorbing species. For these reasons $\mathrm{SF}_{6}$ was found unsuitable as $\mathrm{PM}$ probe gas for the series of zeolites studied here.

\subsection{Conventional $\mathrm{N}_{2}$ and $\mathrm{CO}_{2}$ adsorption isotherms}

Isothermal adsorption curves of $\mathrm{N}_{2}$ at $-196{ }^{\circ} \mathrm{C}$ and $\mathrm{CO}_{2}$ at $0{ }^{\circ} \mathrm{C}$ were recorded to compare with the results obtained by vapor TG and gas PM. For $\mathrm{N}_{2}$ adsorption no complete isotherms were obtained due to very slow pressure equilibration. The $\mathrm{N}_{2}$ isotherms at relative pressure $p / p_{0}<5 \times 10^{-5}$ and the $\mathrm{CO}_{2}$ isotherms are shown in Fig. 5. As for qualitative information directly deductible from the adsorption isotherms, the more discrete adsorption at lower $p / p_{0}$ in zeolites H-ZSM5 as compared to zeolites H-Y corresponds with smaller micropore sizes yielding increased adsorbent-adsorbate interactions [41]. Furthermore, the increased uptake in zeolite $\mathrm{H}$ $\mathrm{Y}_{5.1}$ as compared to $\mathrm{H}-\mathrm{Y}_{80}$ in the first stage corresponds with increasing hydrophilicity facilitating adsorption. However, correlating such subtle isotherm features with one of several competing origins is tricky for unknown micropore structures and in this pore size range the information obtained with vapor TG and gas PM at room temperature is more robust. BET surface areas $A_{\mathrm{BET}, \mathrm{CO} 2}$ as derived from the $\mathrm{CO}_{2}$ isotherms are listed in Table 5. The obtained surface areas are significantly smaller than the theoretical values (Table 2), which already underestimate the reality, and thus appear significantly less accurate than the values obtained by vapor TG and gas PM (Table 4).

\section{Conclusion}

The complementary use of vapor thermogravimetry and gas pycnometry is demonstrated as a method for experimental micropore analysis $<1 \mathrm{~nm}$. The method was validated and calibrated on a series of zeolites with known micropore structures. Quantitative data on accessible pore volumes was obtained by monitoring vapor uptake with TG at room temperature. Using these accessible pore volumes, semi-quantitative data on surface-tovolume ratios and surface areas was obtained by analyzing gas uptake with PM. Micropore cavity sizes were probed by studying competitive uptake of multiple gases with PM. Main advantages of

Table 5

BET surface area $A_{\mathrm{BET}, \mathrm{CO} 2}$, BET correlation coefficient $r$ and BET constant $c$ as derived from $\mathrm{CO}_{2}$ adsorption isotherms at $0{ }^{\circ} \mathrm{C}$ of the zeolites.

\begin{tabular}{|c|c|c|c|c|c|c|}
\hline zeolite & $\mathrm{Ca}-\mathrm{A}_{2}$ & H-ZSM5 30 & H-ZSM5 300 & $\mathrm{H}-\mathrm{B}_{360}$ & $\mathrm{H}-\mathrm{Y}_{5.1}$ & $\mathrm{H}-\mathrm{Y}_{80}$ \\
\hline$A_{\mathrm{BET}, \mathrm{CO} 2}\left[\mathrm{~m}^{2} \mathrm{~g}^{-1}\right]$ & n.d. ${ }^{a}$ & 317 & 359 & 453 & 830 & $850^{\mathrm{b}}$ \\
\hline$r[-]$ & n.d. ${ }^{a}$ & 1.000000 & 0.999976 & 0.999978 & 0.999979 & $0.997605^{\mathrm{b}}$ \\
\hline$c[-]$ & n.d. ${ }^{a}$ & 210 & 121 & 109 & 43 & $13^{\mathrm{b}}$ \\
\hline
\end{tabular}

a Not determined because too few adsorption data points could be obtained due to very slow equilibration.

b The BET plot visibly deviated from linearity. 
the demonstrated method are that diffusion limitations due to cryogenic temperatures are eliminated, adsorption can be studied with non-polar gases, micropore cavity sizes can be probed separate from micropore entrances and data can be interpreted in a straightforward fashion without requiring theoretical models on molecular behavior. With this method, micropores $<1 \mathrm{~nm}$ can be analyzed with increased accuracy as compared to conventional adsorption isotherm analysis.

\section{Notes}

The authors declare no competing financial interest.

\section{Acknowledgements}

Financial support from the Advanced Dutch Energy Materials (ADEM) program of the Dutch Ministry of Economic Affairs, Agriculture and Innovation is gratefully acknowledged. ADEM was not involved in the design, execution or publication of this research. Thanks to Cindy Huiskes and the Inorganic Membranes group of the University of Twente for providing the Autosorb equipment.

\section{References}

[1] U. Stange, M. Scherf-Clavel, H. Gieseler, J. Pharm. Sci. 102 (2013) 4087-4099.

[2] H. Du, M. Kalyanaraman, M.A. Camblor, D.H. Olson, Microporous Mesoporous Mater 40 (2000) 305-312.

[3] S.H. Jhung, J.W. Yoon, J.S. Lee, J.S. Chang, Chem. Eur. J. 13 (2007) 6502-6507.

[4] H.L. Castricum, G.G. Paradis, M.C. Mittelmeijer-Hazeleger, R. Kreiter, J.F. Vente, J.E. ten Elshof, Adv. Funct. Mater 21 (2011) 2319-2329.

[5] S. Saha, B.K. Sharma, S. Kumar, G. Sahu, Y.P. Badhe, S.S. Tambe, B.D. Kulkarni, Fuel 86 (2007) 1594-1600.

[6] H. Huang, K. Wang, D.M. Bodily, V.J. Hucka, Energy \& Fuels 9 (1995) 20-24.

[7] D.L. Moreau, M. Rosenberg, J. Food Sci. 63 (1998) 819-823.

[8] D.L. Moreau, M. Rosenberg, J. Food Sci. 64 (1999) 405-409.

[9] D. Fairén-Jiménez, F. Carrasco-Marín, D. Djurado, F. Bley, F. Ehrburger-Dolle, C. Moreno-Castilla, J. Phys. Chem. B 110 (2006) 8681-8688.

[10] A.G. McDermott, P.M. Budd, N.B. McKeown, C.M. Colina, J. Runt, J. Mat. Chem. A 2 (2014) 11742-11752.

[11] A. Gibaud, J.S. Xue, J.R. Dahn, Carbon 34 (1996) 499-503.

[12] J.M. Calo, P.J. Hall, Carbon 42 (2004) 1299-1304.

[13] J.M. Calo, P.J. Hall, M. Antxustegi, Colloids Surf. A Physicochem. Eng. Asp. 187-188 (2001) 219-232.

[14] M.C. Duke, S.J. Pas, A.J. Hill, Y.S. Lin, J.C. Diniz Da Costa, Adv. Funct. Mater 18 (2008) 3818-3826.
[15] M.P. Petkov, M.H. Weber, K.G. Lynn, K.P. Rodbell, S.A. Cohen, Appl. Phys. Lett. 74 (1999) 2146-2148.

[16] T.H.Y. Tran, H. Schut, W.G. Haije, J. Schoonman, Thin Solid Films 520 (2011) 30-34.

[17] J. Wang, G. Gong, M. Kanezashi, T. Yoshioka, K. Ito, T. Tsuru, J. Memb. Sci. 441 (2013) 120-128.

[18] M. Lépinay, N. Djourelov, H. Marinov, L. Broussous, K. Courouble, C. Licitra, F. Bertin, V. Rouessac, A. Ayral, J. Porous Mat. 21 (2014) 475-484.

[19] M. Kanezashi, K. Yada, T. Yoshioka, T. Tsuru, J. Memb. Sci. 348 (2010) 310-318.

[20] M. Kanezashi, W.N. Shazwani, T. Yoshioka, T. Tsuru, J. Memb. Sci. 415-416 (2012) 478-485.

[21] T. Tsuru, T. Hino, T. Yoshioka, M. Asaeda, J. Memb. Sci. 186 (2001) 257-265.

[22] X. Ren, M. Kanezashi, H. Nagasawa, T. Tsuru, RSC Adv. 5 (2015) 59837-59844.

[23] X. Ren, M. Kanezashi, H. Nagasawa, T. Tsuru, J. Memb. Sci. 496 (2015) $156-164$.

[24] J. Parmentier, S. Schlienger, M. Dubois, E. Disa, F. Masin, T.A. Centeno, Carbon 50 (2012) 5135-5147.

[25] D. Meloni, R. Monaci, D. Perra, M.G. Cutrufello, E. Rombi, I. Ferino, J. Therm. Anal. Calorim. 121 (2015) 1139-1149.

[26] A.S. Al-Dughaither, H. De Lasa, Ind. Eng. Chem. Res. 53 (2014) 15303-15316.

[27] K.C. Kim, T.-U. Yoon, Y.-S. Bae, Microporous Mesoporous Mater 224 (2016) 294-301.

[28] D. Cazorla-Amorós, J. Alcañiz-Monge, M.A. De La Casa-Lillo, A. Linares-Solano, Langmuir 14 (1998) 4589-4596.

[29] R. Rouquerol, J. Rouquerol, K.S.W. Sing, P. Llewellyn, G. Maurin, Adsorption by powders and porous solids, in: Principles, Methodology and Applications, second ed., Academic Press, Elsevier Ltd, Oxford, 2014.

[30] M.R. Baklanov, K.P. Mogilnikov, V.G. Polovinkin, F.N. Dultsev, J. Vac. Sci. Technol. B 18 (2000) 1385-1391.

[31] A. Bourgeois, A. Bondaz, L. Kitzinger, C. Defranoux, ECS Trans. 16 (2008) 221-229.

[32] M. Lépinay, L. Broussous, C. Licitra, F. Bertin, V. Rouessac, A. Ayral, B. Coasne, Microporous Mesoporous Mat. 217 (2015) 119-124.

[33] R.C. Hedden, H.-J. Lee, C.L. Soles, B.J. Bauer, Langmuir 20 (2004) 6658-6667.

[34] V. Rouessac, A. van der Lee, F. Bosc, J. Durand, A. Ayral, Microporous Mesoporous Mat. 111 (2008) 417-428.

[35] J.R. Anderson, K. Foger, T. Mole, R.A. Rajadhyaksha, J.V. Sanders, J. Catal. 58 (1979) 114-130.

[36] S.V. Awate, P.N. Joshi, V.P. Shiralkar, A.N. Kotasthane, J. Incl. Phenom. Mol. Recognit. Chem. 13 (1992) 207-218.

[37] J.D. Moyer, T.R. Gaffney, J.N. Armor, C.G. Coe, Microporous Mater 2 (1994) 229-236.

[38] A. Corma, C. Corell, J. Pérez-Pariente, J.M. Guil, R. Guil-López, S. Nicolopoulos, J. Gonzalez-Calbet, M. Vallet-Regi, Zeolites 16 (1996) 7-14.

[39] International Zeolite Association Structure Commision, Database of zeolite structures. http://www.iza-structure.org/databases/, accessed Dec 2016.

[40] L.W. Beegle, I. Kanik, L. Matz, H.H. Hill, Int. J. Mass Spectrom. 216 (2002) 257-268.

[41] R. Rouquerol, J. Rouquerol, K.S.W. Sing, P. Llewellyn, G. Maurin, Adsorption by powders and porous solids, in: Principles, Methodology and Applications, second ed., Academic Press, Elsevier Ltd, Oxford, 2014, pp. 303-320. 